\title{
Revitalizing primary health care - another utopian goal?
}

\section{Marahatta SB ${ }^{1}$}

${ }^{1}$ Department of Community Medicine, Kathmandu University Hospital, Kavre, Nepal

\section{Corresponding author}

Sujan B Marahatta

Department of Community Medicine

Kathmandu University Hospital, Kavre, Nepal

Email: sujanmarahatta@gmail.com

Kathmandu Univ Med J 2010;8(31):341-51

\begin{abstract}
The quest for greater efficiency, fairness and responsiveness to the expectation of the people that system serve have brought about three generations of health system reforms in the twentieth century. The first generation saw the founding of national health care systems and extension to middle income nations of social insurance systems in the 1940s and 1950s. By the late 1960s the rising costs of hospital based care, its usage by better off, inaccessibility by the poor and rural population of even the most basic services heralded second generation reforms promoting primary health care as a means of achieving the affordable universal coverage. It included the best public health strategy that is prevention and the highest ethical principle of public health that is equity. It was expected the best system for reaching households with essential and affordable care, and the best route towards universal coverage. The primary health care approach though adopted universally did not materialize its notion of translating ethos of Health for All by 2000. Overall, primary health care movement by the end of 20th century became lifeless. Since the Declaration of Alma-Ata, fundamental changes have occurred affecting health service delivery, such as economic development and financing approaches, globalization of trade and knowledge, and the shift to privatization. This is the time to develop a new vision, taking into consideration the many changes affecting global health and the strategic developments in health of recent years. With this recognition, the third generation of reforms now underway in many countries is driven by the idea of responding more to demand, assuring access for the poor and emphasizing financing rather than just provision within the public sector. The key concern is: how to translate ethos of revitalizing in the reality. Otherwise the revitalizing concept will turn into utopian goal so like HFA by 2000 strategy.
\end{abstract}

Key words

health system, primary health care, reform

\section{INTRODUCTION}

The great advances in the field of public health coupled with the enrichment in health care practices made in the last half of the nineteenth century which, in tandem with the rapid economic growth resulted in significant health gains, as evidenced by the global increase in life expectancy and in total adult literacy, and the reduction in infant mortality and under-5 mortality. By the end of the twentieth century, biomedical sciences and clinical medicine have achieved phenomenal advancement and successes with new and ever improving diagnostic, pharmacological and instrumental armamentaria, which offered increasingly effective and powerful technologies to combat diseases. ${ }^{1}$ Indeed, the human health has probably improved more over the past century than over the previous three millennia. On one hand, health technology is so advanced that various organ transplantations are possible, and health science has successfully mapped genes; on the other hand people are dying from easily preventable and curable diseases.
The dawn of the twenty-first century has evoked opportunities and threats to health system, a situation with hope intermingled with uncertainty. Over a billion people entered the new century without having benefited from health revolution, their lives being short and scarred by diseases. Of the 4.4 billion people in the developing countries nearly three fifths lack access to sanitation, a third don't have clean water, a fifth do not have enough dietary energy and protein. ${ }^{2}$

The health care system across the globe are plagued by inequitable and unequal access to health services, double burden of the diseases imposed by communicable diseases and life-style related conditions, emergence of the newer public health problems attributed by improper developmental endeavors as well as indiscriminate and unharmonious use of the natural resources. These challenges demand reorientation of our health policies, equitable distribution of resource, total coverage of the population with focus on marginalized/vulnerable groups, 
carefully designed intersectoral approach, application of the appropriate technology and full community involvement. $^{3}$

The quest for greater efficiency, fairness and responsiveness to the expectation of the people that system serve have brought about three generations of health system reforms in the twentieth century. The first generation saw the founding of national health care systems and extension to middle income nations of social insurance systems in the 1940s and 1950s. However by the late 1960s the rising costs of hospital based care, its usage by better off, inaccessibility by the poor and rural population of even the most basic services heralded second generation reforms promoting primary health care as a means of achieving the affordable universal coverage. In 1978 PHC was adopted as the strategy for achieving goal of Health for All by $2000 .^{4}$

Primary health care became the hub of national health system in many countries, with establishment of primary health care units generally employing mid level health workers. PHC is a blend of activities, approach and level of health care. It had eight elements, known as basic health care, to be conducted on the basis of equity, community involvement, appropriate technology and multisectorial approach. ${ }^{5}$ As a set of activities, primary health care depends on synergy. The health system based on primary health care focuses on improving the overall health of the population rather than just the treatment of disease. The original eight primary health care elements considered essential were immunization, health education, nutrition, safe water and basic sanitation, maternal and child health care including family planning, prevention and control of locally endemic diseases, appropriate treatment of common diseases and injuries and provision of essential drug. ${ }^{6}$ It relied on the foundation that most community health problems can be resolved by lower level of health care which can be made affordable, accessible and acceptable to the community. It included the best public health strategy that is prevention and the highest ethical principle of public health that is equity. It was expected the best system for reaching households with essential and affordable care, and the best route towards universal coverage.

Of course, inspiration and guidance of Alma Ata conference gave global impetus to adopt PHC model as key attainment of HFA by 2000, yet it was not translated in real ground. In this regard, though health system in some countries performed well, other did poorly. Large number of people fail to realize their full potential of better health because health system allocated resources to intervention of low quality and low efficacy.
The two major challenges confronting all countries are how to ensure efficiency in the mean time how to maintain universal coverage to quality services. Countries had to seek to diversify the resources of service provisions and select intervention, that for the resources each county choose to commit, will provide equitable distribution and maximum gain in health level. Cost effective intervention need to be tailored according to the public finance reality of each country. There is now doubt that poverty, debt and structural adjustment policies have led many developing countries to decrease public expenditure in health care, consequently financing burden falling disproportionally on the poorest restricting their access to health services despite their health need being greater. The period of economic hardship that many countries experienced had coincided with their ambitious goals for the development of primary health care system. ${ }^{2}$

Two major schools of thought dominated the debate: those supporting "selective" primary health care (SPHC) and those advocating "comprehensive" primary health care (PHC). The advocates of selective primary health care stated that the large and laudable scope of the Alma Ata Declaration was unattainable due to its prohibitive cost and the numbers of trained personnel required to implement the approach. A more selective approach would attack the most severe public health problems facing a locality in order to have the greatest chance to improve health and medical care in less developed countries.?

The advocates of comprehensive primary health care emphasized that the improvement of health care delivery systems is only one aspect of the reforms needed. It incorporates a philosophy of health and health care as basic human right that, if necessary, also requires the re-shaping of global developmental designs to include community participation in the decision-making and the implementation of primary health care activities. Although improvements in the health sector are very important "most improvements in health have been due to changes in economy, social and political structures rather than changes in the health sector" ${ }^{8}$ This debate extends earlier arguments about whether the best method of health care delivery was "vertical" or "horizontal".

The "horizontal approach" seeks to tackle the overall health problems on a wide front and on a long-term basis through the creation of a system of permanent institutions commonly known as "general health services". The "vertical approach" calls for the solution of a given health problem through the application of specific measures. In essence, horizontal programmes are person- and communityfocused, whereas vertical programmes are disease-focused. The selective strategy has been favorably received by international agencies such as World Bank and UNICEF, 
academic institutions and research centres (e.g. Centres for Disease Control), bilateral aid-agencies like USAID, and private institutions).$^{10}$

The primary health care approach though adopted universally did not materialize its notion of translating ethos of Health for All by 2000. Overall, primary health care movement by the end of 20th century became lifeless. There are many reasons behind this demise ranging from global to local. The review came out with the following reasons responsible for unsuccessful implementation of primary health care- lack of community participation, lack of intersectoral collaboration, lack or misuse of human resources and material resources, concentration on sophisticated technology, mismanagement and lack of inter country collaboration and lack of operational research. ${ }^{6}$

The main global factor were the 1980s global economic recession followed by government reduction in public spending and commercialization of health care; political clash between communism and capitalism; favourism of disease oriented vertical interventions by major donors and pharmaceuticals. At national level, implementation of PHC faced inadequate political commitment, lack of adequate supplies and human resources, difficulty in intersectoral co-ordination, in community involvement, retaining health workers in peripheral health care units, and opposition by powerful medical and nursing associations. ${ }^{11}$

Since the Declaration of Alma-Ata, fundamental changes have occurred affecting health service delivery, such as economic development and financing approaches, globalization of trade and knowledge, and the shift to privatization. Pressures on health systems include demographic change, changing disease patterns, increased environmental hazards, emerging technologies, global communication networks and increased expectations of users. All these changes have further increased the critical importance of primary health care and its central role in sustainable development. This is the time to develop a new vision, taking into consideration the many changes affecting global health and the strategic developments in health of recent years. At the same time it should build on previous experiences and existing, specific socioeconomic realities.

WHO states that community participation was one of the tenets of PHC, the movement focused almost exclusively on presumed health care needs of the people and did not emphasize enough attention to their demands. Therefore, the third generation of reforms now underway in many countries is driven by the idea of responding more to demand, assuring access for the poor and emphasizing financing rather than just provision within the public sector. ${ }^{4}$
The focus of the global health community is shifting from a biological to a social model of health, from vertical to horizontal programmes, and towards health system strengthening. That means that values, principles and approaches of $\mathrm{PHC}$ have been again reaffirmed as the best cost-effective way of achieving quality of life. ${ }^{11}$ In 2000 world leaders reached a consensus on a new movement, termed Millennium Development Goal (MDG), to be achieved by 2015 . Five out of eight goals are health related. WHO sees MDG as milestones on the road to HFA since they set clear and distinct target compared to HFA. South East Asia Region of WHO, conference took place during 6-8 of August, 2008 in Jakarta, Indonesia to revitalize Primary Health Care. The conference proposed the road map of achieving health goals by the member countries as well as MDGs through health system strengthening using PHC approach, taking into consideration social determinants of health. ${ }^{12}$ The key concern is-how to translate ethos of revitalizing in the reality. Otherwise the revitalizing concept will turn into utopian goal so like HFA by 2000 strategy.

WHO recognized that health systems need to respond better and faster to people's demands and to the challenges of a changing world and that the values of Alma-Ata Declaration to adopt PHC approach to achieve, HFA may respond to the people's demand and expectation. WHO demands renewal of $\mathrm{PHC}$ with four sets of reforms:

a) Universal coverage reforms to improve health equity, b) service delivery reform to make health systems people centered, c) leadership reforms to make health authorities more reliable and d) public policy reforms to promote and protect health of communities. ${ }^{13}$

As a concept PHC offers a comprehensive guide on equity, what to prioritize, technology to be applied, sociocultural aspects, target groups, full involvement of the community, cost effectiveness and efficiency. Perhaps due to its rich and comprehensiveness nature, PHC is oftentimes misperceived. Many misperceive PHC as cheap, second grade health care, health care at grassroots level, health care for rural and the poor, healthcare in developing countries, etc. These misperceptions to some extent are understandable considering that $\mathrm{PHC}$ has a multiplicity of meanings depending on which perspective we look: a) a package or a set of activities, b) level of care and c) an approach which has been termed interchangeably PHC principle, PHC pillar and PHC strategy. The Jakarta conference reaffirmed $\mathrm{PHC}$ is the right approach to strengthen health systems and address national health needs. Furthermore, a shift from a focus on service delivery to a developmental, people centered approach keeping in mind the social, political and economic context. ${ }^{7}$ 


\section{CONCLUSION}

Health care reform for the 21st century should aim to achieve health for all through people centered equitable care, ensuring universal coverage and social protection eventually improving health status and health equity. In other word the vision of health care reform is a healthier population with good living and working conditions, healthy living environment, suitable housing, good personal health practices and coping skills, affordable health services accessible to all, and prevention of illness, injury and death.

\section{REFERENCES}

1. Solyom EA. Contemporary challenges of medical education: morality and integrity of physicians [Place Unknown] [Publisher Unknown]; [cited 2009 Nov 1] Available from: http://www.ishm2006.hu/scientific/abstract.php?ID=290

2. Marahatta SB. New Universalism: A Paragon of Health System. Health Prospect. 2000;1:3-4.

3. Royal Government of Bhutan. Speech of Lyonpo Zangley Dupka WHO Regional Meeting on Health Care reforms for 21st Century Bangkok, Thailand, 20-22 October, 2009.

4. World Health Organisation. World health report 2000: health systems: improving performance. Geneva: WHO, 2000.

5. World Health Organisation. Speech of Margaret Chan in Primary Health Care Conference in Buenos Aires, Argentina, 16 August, 2007.

6. World Health Organisation. Primary Health Care: 25 years after Alma-Ata: WHO regional office for Mediterranean region, 2003.

7. Walsh JA, Warren KS. Selective Primary Health Care: an interim strategy for disease control in developing countries. Soc Sci Med 1980;14:145-63.

8. Navarro V. A critique of the ideological and political position of the Brandt Report and the Alma Ata Declaration. Int J Health Serv 1984; 14:159-72.

9. Loeliger SF. On programs, processes, approaches and movements: a critical analysis of PHC, supported by a case study in Fiji. MSc-thesis, Berkeley, University of California, Department of health and medical sciences, 1987.

10. Unger JP, Killingsworth JR. Selective primary health care: a critical review of methods and results. Social Soc Sci Med 1986;22:1001-13

11. Karkee R. Revitalizing primary health care. Kathmandu Univ Med J 2008;6:297-300.

12. World Health Organisation. Regional conference in revitalizing primary health care, Jakarta Indonesia, 6-8 August 2008. New Delhi: WHO-SEARO, 2008.

13. World Health Organisation. World health report 2008: primary health care now more than ever. Geneva: WHO, 2008. 